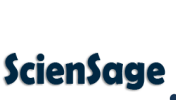

Journal of Advanced Scientific Research

Available online through https: / /sciensage.info
ISSN: 0976-9595

Research Article

DOI: $10.55218 /$ JASR. 202213113

\title{
MICELLIZATION BEHAVIOUR OF CONVENTIONAL (SDS AND DTAB) AND SYNTHESIZED GEMINI SURFACTANT (12-2-12) IN AQUEOUS SOLUTIONS OF METFORMIN HYDROCHLORIDE AT VARYING TEMPERATURES: A COMPARATIVE STUDY
}

\author{
Meenakshi Kumari ${ }^{1}$, Punita Sharma*1, D.S. Rana ${ }^{2}$, Kuldeep Singh ${ }^{3}$ \\ ${ }^{1}$ Department of Chemistry, Maharaja Agarasen University, Solan, Himachal Pradesh, India \\ ${ }^{2}$ Department of Environmental Sciences, Central University of Himachal Pradesh Dharamshala, Himachal Pradesh, India \\ ${ }^{3}$ Department of Chemistry, MCM DAV College Kangra, Himachal Pradesh, India \\ *Corresponding author:punitasrm@gmail.com
}

\begin{abstract}
The micellar properties of two common surfactants, namely sodiumdodecyl sulphate (SDS) which is of anionic character and dodecyltriamonium bromide (DTAB) of cationic type alongwith 12-2-12 gemini surfactant which was produced in aqueous solutions of $0.001,0.005$ and $0.01 \mathrm{~mol} \cdot \mathrm{kg}^{-1}$ aqueous solutions of metformin hydrochloride $(\mathrm{Mfm}-\mathrm{HCl})$ (antidiabetic drug) at 25, 35 and 45 degree Celsius has been analyzed through conductometry. The obtained conductivity data has been used to determine one of the most important characteristic of surfactants known critical micelle concentration (CMC); the concentration above which micelles are formed. The variation in CMC with content of metformin hydrochloride has been compensated in terms of hydrophobic interactions. The drug has been found to diminish the $C M C$ of both types of surfactants (conventional and synthesized). In terms of the hydrophilic/hydrophobic interactions existing in the system, the effect of temperature on the micellization behaviour of these discussed surfactants has also been studied. Moreover, energetics of micellization has also been discussed by using phsedo-phase separation model for all the studied systems in terms of thermodynamic parameters viz. standard enthalpy, $\Delta H_{m}^{o}$ free energy, $\Delta G_{m}^{o}$ and entropy, $\Delta S_{m}^{o}$ of micellization and viewed in terms of different interactions that may exist in the system. The influence on the micro polarity of micellar environment has been discussed by pyrene probe fluorescence technique and used to determine $C M C$ which has been discovered to have a strong resemblance to conductivity studies.
\end{abstract}

Keywords:Conductometry, Micellization, Thermodynamics, Critical micelle concentration, Hydrophobic interactions.

\section{INTRODUCTION}

Surfactants (surface active agents) are amphiphilic chemicals with the ability to bind to surfaces. They are essential components in biological and pharmaceutical processes, and so account for a significant amount of consumption in industrial and commercial applications. [1-4]. Due to peculiar property of binding at interfaces, they are utilized to number of purposes ranging from household utility to various industrial as well as biological processes. As far as the industrial applications of surfactants are concerned they are used as cleaning agents, in flotation, in washing and enzymatic processes, in agrochemical formulations and in personal care products [5-7]. In biology, however, they are used as a drug carrier or penetration enhancer to tackle the problem of medications' low solubility/permeability. Because the pharmacological activity of a medication is only noticed when it reaches the site of action, medicines must have a reasonable solubility/ permeability [8]. The unique property of surfactants to bind at surfaces hence their utilization as penetration enhancer is due to amphiphilic character i.e. presence of aquaphobic (solvophobic) as well as aquaphilic (solvophobic) groups on them. The hydrophobic/ hydrophilic character of surfactants is induced due to the presence of non-polar (hydrophobic) hydrocarbon chain and polar head groups on them. This kind of structure is responsible for their water repelling as well as water attracting charcter. Upon dissolution of these amphiphiles in water they start to aggregate (micellezation) and form self assembled structures of peculiar shape such as spherical, hexagonal, lamellar etc. with different size [9]. Critical micelle concentration (CMC) is the minimal surfactant concentration at which 
aggregation occurs $[10,11]$. These micelles are the main transporter for drugs and hence may resolve solubility/permeability complication to some extent.

However, new kinds of surfactants known as gemini surfactants have been replacing them in recent years due to their superiority in terms of surface activity over conventional surfactants. [12,13]. Gemini surfactants also outperform other surfactants when it comes to surface activity, such as aggregation behaviour (micellization), solubility, and efficacy in lowering interfacial tension. $[14,15]$. The better surface activity of gemini surfactants also encourages the pharmaceutical industries to incorporate them to be used as penetration/solubilization enhancer so as to challenge solubility/permeability difficulties with the pharmaceutical formulations [16-18]. Thus, it would be interesting to study the surfactants (conventional or gemini) in combination with drugsin an attempt to enhance the utilization of these compounds. In order to do so, we used metformin hydrochloride as a model medication to investigate the micellazation behaviour of three diverse types of surfactants:cationic (DTAB), anionic (SDS), and gemini surfactant (12-2-12). These compounds' chemical structures have been provided in scheme 1.

Metformin hydrochloride (Mfm- $\mathrm{HCl})$ is an antihyperglycaemic/antidiabetic drug that belongs to the biguanidine class and has a high solubility but low permeability, falling under Biopharmaceutical Classification System (BCS) class III [19]. From a long time, It's been used to treat non-insulin-dependent diabetic mellitus (type 2 diabetes mellitus). It is also recognized to have antioxidant, anti-tumorigenic, and anticancer properties in addition to its glucose-lowering properties [20, 21]. It is prescribed as a blood glucose lowering agent even prior to developing persistent hyperglycaemia. $\mathrm{Mfm}-\mathrm{HCl}$ is also used to treat polycystic ovarian syndrome (PCOS) [22].

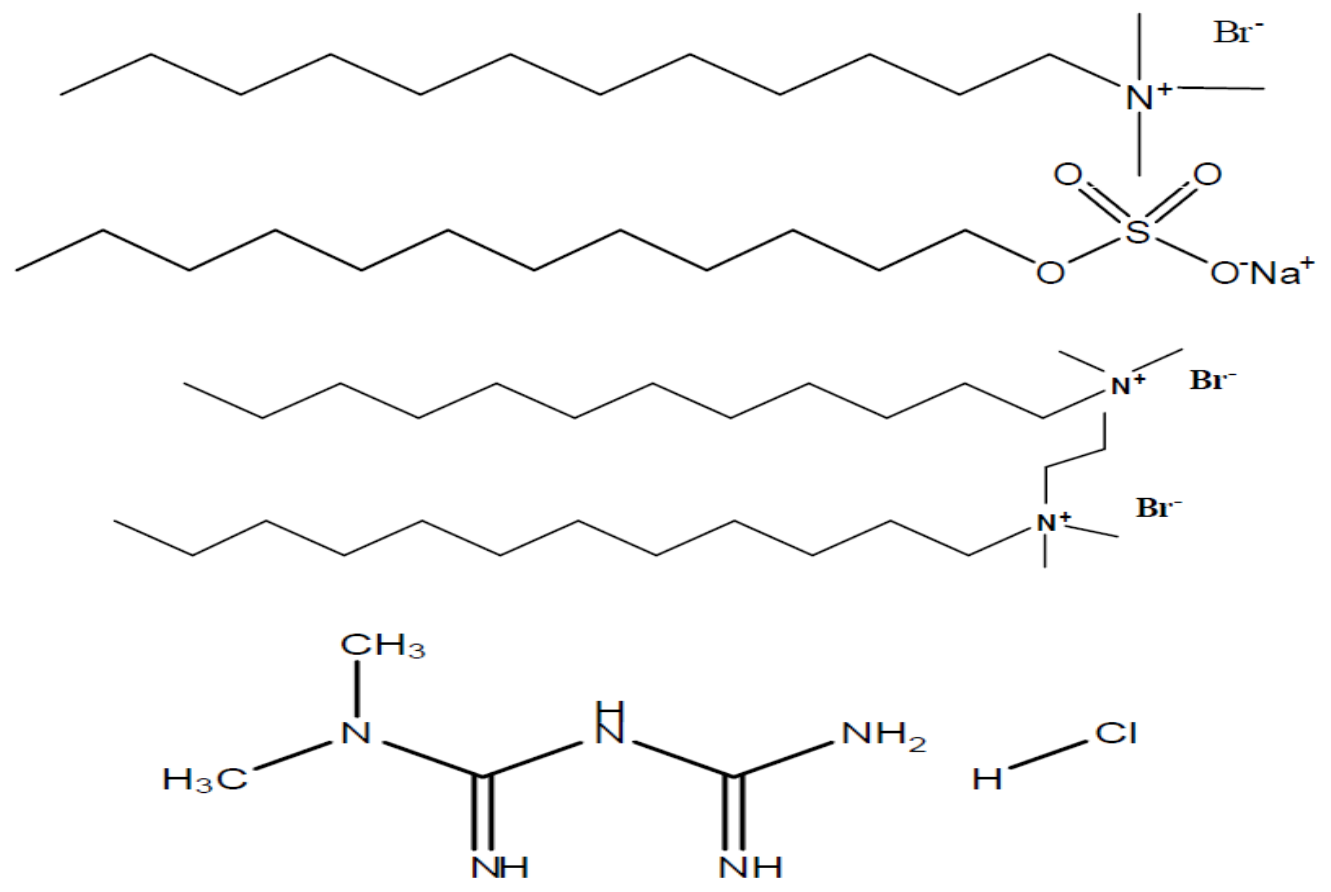

\section{Scheme 1:Chemical structures of a) SDS, b) DTAB, c) 12-2-12 Gemini surfactant and d) Mfm-HCl}

It is the only anti-diabetic medicine that has been proven to reduce diabetes-related cardiovascular problems [23]. Chemically, It is an N,N-dimethylimidodicarbonimidicdiamide that is freely soluble in water, methanol, but not acetone or ether [24].

Thus, in the present work, We have tested the aggregation modulation of a generated cationic 12-2-12 gemini surfactant, i.e. ethanediyl-1,2-bis (dimethy- ldodecylammonium bromide) and industrially important surfactants sodiumdodecyl sulphate (SDS) and dodecyltrimethyltrimethylam-monim bromide (DTAB) in $0.001,0.005$ and $0.01 \mathrm{~mol} \cdot \mathrm{kg}^{-1}$ aqueous solutions of metformin hydrochloride $(\mathrm{Mfm}-\mathrm{HCl})$ by making use of electrical conductometry. To have a better understanding of the peculiar behaviour, the thermodynamic parameters were calculated and 
examinedand the energetic of micellization of considered surfactants in aqueous medium of drugby carrying out the conductivity measurements at 298.15, 308.15 and $318.15 \mathrm{~K}$. The pyrene probe analysis has also been done to corroborate the results of conductivity study. The study may be very helpful in pharmaceutical formulations and to enhance the applicability of surfactants.

\section{EXPERIMENTAL}

\subsection{Material}

Metformin hydrochloride, purified to 99.66 percent purity, was obtained from Schwitz Biotech and was used without any further treatment. 12-2-12 gemini surfactant [ethanediyl-1,2-bis(dimethyldodecylammonium bromide)] has been synthesized with the help of mixture of $\mathrm{N}, \mathrm{N}, \mathrm{N}, \mathrm{N}$-tetramethyl ethylene diamine (TEMED) and 1-bromododecane (molar ratio of 1:2). The complete procedure and characterization of produced 12-2-12 gemini surfactant has been given in our earlier publication [25]. Analytical reagent grade, SDS and DTAB was gotten from S D Fine-Chem. Ltd. Having purity $>99 \%$. After recrystallization from ethanol, both surfactants were utilised to conduct studies for carrying out experiments. In a typical experiment employed for recrystallization; $50 \mathrm{~g}$ SDS was dissolved in $500 \mathrm{~mL}$ A.R. grade ethanol, then filtered to remove any suspended contaminants. Following filtering, the solution was gently heated over a water bath until it was reduced to a quarter of its original volume. For roughly 2 hours, the solution was allowed to cool to ambient temperature. Pure SDS needles with a white shaded appearance appeared shortly after the solution reached room temperature. The sample was decanted and recrystallized from ethanol at least twice before being dried under vacuum in the presence of $\mathrm{P}_{2} \mathrm{O}_{5}$ at about $50-60^{\circ} \mathrm{C}$ for $24 \mathrm{hr}$ in vacuum oven [26]. Without further purification, A.R. grade pyrene was utilised as a probe for evaluating fluorescence spectra of the materials. The major solvent in this study is double distilled water, which was obtained from a Millipore-Elix distillation unit. All of the studies were carried out using water with a conductivity range of 2 to $3 \mathrm{Scm}-1$ and a $\mathrm{pH}$ of 6.8 to 7.0 at $298.15 \mathrm{~K}$.

\subsection{Instrumentation}

\subsubsection{Conductometry}

Conductivity tests were achieved with the help of a sophisticated and advanced conductivity meter Con-510
Cyberscan. The limiting molar conductance, $\Lambda_{\mathrm{o}}$ values of $\mathrm{NaNO}_{3}, \mathrm{AgNO}_{3}, \mathrm{Bu}_{4} \mathrm{NI}, \mathrm{Bu}_{4} \mathrm{NBr}$ and $\mathrm{NaBPh}_{4}$ in DMSO were used to calibrate the device at $298 \mathrm{~K}$.

These electrolytes' $\Lambda_{\mathrm{o}}$ values were obtained to be 41.1, 44.0, 36.0, and $35.8 \mathrm{~S} \mathrm{~cm}^{2} \mathrm{~mol}^{-1}$, respectively, which were quite similar to those described in the literature. [27-31]. By cycling thermostated water through a double walled vessel containing the experimental solution, the temperature of the solution was kept constant up to $0.1 \mathrm{~K}$. The circulation was done with the help of a high- powered digital water circulator provided by Riviera Pvt. Ltd., Mumbai. Before collecting the measurements, the sample was allowed to reach the temperature of the thermostat.

\subsubsection{Fluorescence Probe Studies}

The LS-55 Perkins Elmer Fluorescence Spectrophotometer was used to conduct the fluorescence probe analysis by fixingthe excitation wavelengthat $334 \mathrm{~nm}$ and excitation slit at $8.0 \mathrm{~nm}$, while Surfactant emission in the presence of pyrene was measured at 373 and 384 $\mathrm{nm}$ with emission slits at $2.5 \mathrm{~nm}$.As a fluorescent probe, pyrene solution with a concentration of $2 \times 10^{-6}$ $\mathrm{mol} \cdot \mathrm{kg}^{-1}$ was utilised.

\subsubsection{Methods}

The conductivities $(\kappa)$ of the solution of SDS, DTAB and 12-2-12 gemini surfactant over a wide range of their concentrations in $0.001,0.005$ and $0.01 \mathrm{~mol} \cdot \mathrm{kg}^{-1}$ aqueous solutions of metformine hydrochloride. For weighing the chemicals for solution preparation, a Shimadzu balance with a precision of $0.0001 \mathrm{~g}$ was adopted.Using a $10-100 \mu \mathrm{L}$ eppendorf micropipette, a known volume of concentrated stock solution of SDS, $\mathrm{DTAB}$, and 12-2-12 gemini surfactant was added to the known volume of solvent in a double walled tank to modify the concentration of the solution. The experiment was reiterated thrice with similar stock arrangements of both mentioned surfactants.

For spectral analysis (fluorescence probe analysis) pyrene solution of $2 \times 10^{-6} \mathrm{~mol} \cdot \mathrm{kg}^{-1}$ concentration was used. Pyrene solution was made by adding a known weight of ethanol to a known weight of pyrene solution. The mixture was sonicated to yield a clear solution [32]. Dilution was used to make the needed $\left(2 \times 10^{-6} \mathrm{~mol} \cdot \mathrm{kg}^{-1}\right)$ pyrene solution for the experiment, which had a 0.5 percent ethanol concentration. The pyrene solution was put into vials $(1 \mathrm{ml}$ each) after being sonicated for around five minutes and maintained for a while to evaporate the ethanol (1/3rd). The minimal amount of 
ethanol remained is thought to have no effect on the amphiphiles' spectrum and self-aggregation behaviour. Now, the desired surfactant solutions were put into these vials and swirled for roughly 6 hours to ensure that the hydrophobic pyrene was completely dissolved in the surfactant solutions. The fluorescence spectra of these solutions were measured in the $350-450 \mathrm{~nm}$ region. All of the measurements were taken at a temperature of $298.15 \pm 0.1 \mathrm{~K}$. The instrument's sensitivity is measured in terms of the signal-to-noise ratio, which is 500:1 r.m.s.

\section{RESULTS AND DISCUSSION}

\subsection{Conductivity Measurements}

\subsubsection{Critical Micelle Concentration (CMC) Deter- mination}

Conductometry [33] is one of the most capable techniques for determining surfactant association behavior/critical micelle concentration in the presence of an additive [33]. The conductivity, $\kappa$ values data of sodium dodecyl sulfate (SDS), dodecyltrimethylammonium bromide (DTAB) and its dimer (of DTAB) 12-212 gemini surfactant i.e. ethanediyl-1,2-bis(dimethyl dodecyl ammonium bromide) in 0.001, 0.005 and $0.010 \mathrm{~mol} \cdot \mathrm{kg}^{-1}$ aqueous solutions of metformin hydrochloride at 298.15, 308.15 and $318.15 \mathrm{~K}$ have been summarized in table S1 of supplementary data. However, the represented plots of conductivity plotted against the surfactant concentration have been shown in fig. 1. From these plots, it can be seen that conductivity increases sharply with [surfactant] upto a certain concentration, however, changes slowly after it. At low concentration, the variation of conductivity can be compensated in terms of mobility of the constituents present in the mixture solution. At low concentration surfactant behaves as electrolytes and according to Onsager theory of electrolyte [34-36] the electrolytes (surfactants) upon dissolution get dissociated into ions which move in solution and their movement is responsible for the conductivity of the solution. At low concentration, the ions are free to move due to free space in solution and hence have higher $\kappa$ values (sharp increase). The number of ions increases with content of the surfactant and hence $\kappa$ values increases. But at higher concentration after particular surfactant content, the aggregation of surfactants (micelle formation) takes place and In the stern layer of micelle microstructure, a fraction of counter ions condensesthat inhibit the movement of ions resulting into slow increase in conductivity values [37]. Also, augmentation in $\kappa$ values with different magnitude before (pre-micellar region) and after (post-micellar region) a particular point can be explained by the fact that the presence of micelles in the post micellar region restricts movement, resulting in a smaller contribution to conductivity than in the pre-micellar region, where only ions are present (no micelles). The intersection points between the two straight lines drawn in pre- and post-micellar regions gives the value of critical micelle concentration (CMC) [38]. Initially, Electrostatic and hydrophobic interactions after $\mathrm{CMC}$ formation play a crucial role in the development of micelles. Here, it is important to mention here that the breakpoint is very sharp unscramblingpre- and post-micellar regions. However, there are a few examples $[39,40]$ of like binary ionic surfactant combinations where the breakpoint in the conductivity curve is broad. This can be usuallydescribed on the basis of two situations (i) progressive micellization occurs instead of an instantaneous micelle production process, as in the case of all bile salts [41] or in the presence of organic additives [42] (ii) When bilayer assembly [43] or insoluble salt production occurs in addition to conventional spherical micelles, for example, as in the case of oppositely charged ionic surfactants' binary combinations. The conductivity values of SDS, DTAB and 12-2-12 gemini surfactants increases with concentration of drug. This is obvious due to the content of drug there is an increase in ionic species hence mobility increases. Comparatively, the conductivity values follow the order; SDS $<$ DTAB $<$ 12-2-12 geminisurfactant at similar concentration, which can be compensated in terms of more number of ions and size of the surfactants.

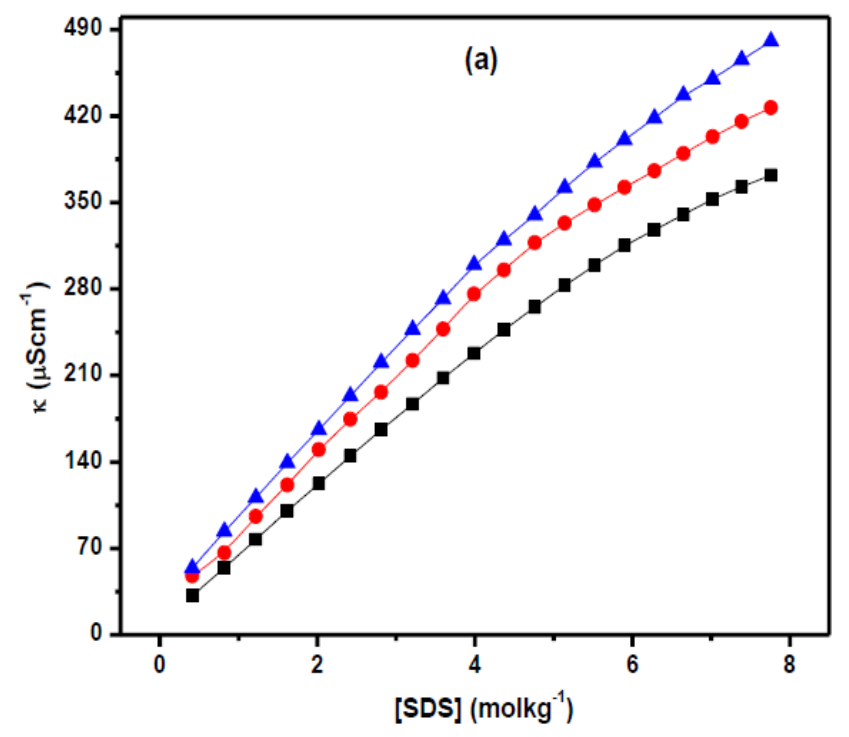



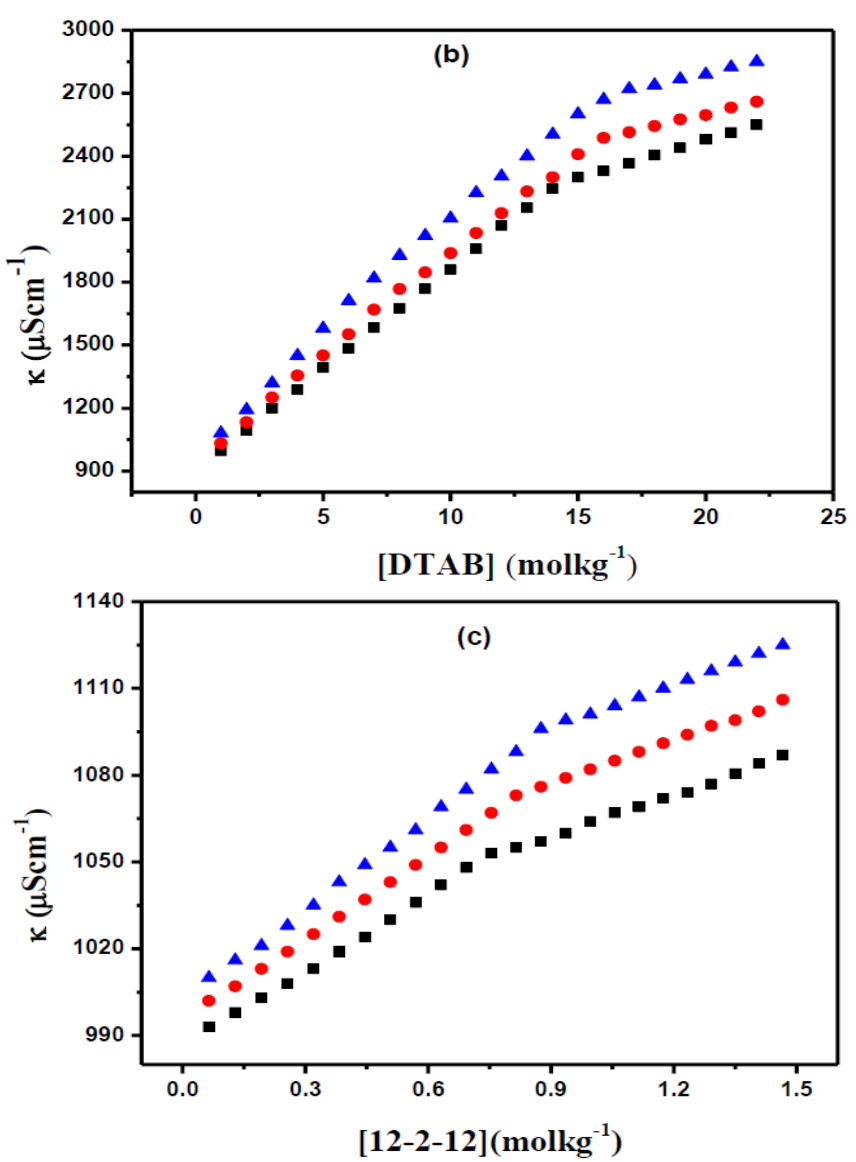

Fig. 1:Representative plots of $\kappa$ vs. concentration of a) SDS in b) DTAB and c) 12-2-12 gemini surfactant in $0.010 \mathrm{~mol} \cdot \mathrm{kg}^{-1}$ aqueous solution of metformin hydrochloride at298.15 K $(\square), 308.15 \mathrm{~K}(\bullet)$ and $318.15 \mathrm{~K}(\Delta)$ ).

The values of critical micelle concentration (CMC) derived from conductivity measurements have been tabulated in table 1. From $C M C$ values it is noticeable thatvalues of $\mathrm{CMC}$ in the presence of $\mathrm{Mfm}-\mathrm{HCl}$ decreases for all the surfactants. The drug content effectively reduces the $C M C$ values of all the surfactants and follows the order:0.001 $>0.005>0.010 \mathrm{~mol} \cdot \mathrm{kg}^{-1}$ aqueous solutions of metformin hydrochloride. This can be compensated in terms of modulation in various kinds of interactions induced by drug that causes the dehydration of hydrophilic that make it easier for the surfactant molecule to approach each other i.e. easy aggregation. Also, The presence of a large number of amine functional groups on $\mathrm{Mfm}-\mathrm{HCl}$ promotes better interactions and, as a result, micellization occurs sooner.Because hydrophobic interactions are the fundamental driving force for micellization, the hydrophobicity given by drug molecules appears to diminish CMC values of all surfactants studied.The existence of hydrogen bonding between the $-\mathrm{H}\left(-\mathrm{NH}_{2}\right)$ of the medication and the $-\mathrm{O}\left(\mathrm{SO}_{4}\right)$ of the SDS moiety may also account for the decrease in CMC of surfactantsas well as because of the hydrophobic contact between the hydrophobic tails of the surfactants and the hydrophobic chain and branching groups of the medication, micellization occurs before it happens in water [44]. Moreover, $\mathrm{Mfm}-\mathrm{HCl}$ has a tendency to encourage the formation of a water matrix, which decreases the degree of hydrophilic hydration, encouraging micellization and lowering the $C M C$ values [45].Comparatively, the $C M C$ values follow the order: 12-2-12 gemini surfactant $<$ SDS $<$ DTAB. The observed trend may be accredited to the difference in these surfactants' hydrophobic character. As 12-2-12 gemini surfactant is most hydrophobic in nature and hence posses lowest $C M C$ values.

Table 1: CMC of SDS, DTAB and 12-2-12 gemini surfactant in $\left(\mathrm{m}^{\mathrm{a}}=0.001,0.005\right.$ and 0.010$) \mathrm{mol}^{\cdot} \mathrm{kg}^{-1}$ aqueous solutions of metformin hydrochloride at different temperatures ( $T / K)$.

\begin{tabular}{|c|c|c|c|c|c|c|}
\hline \multirow{2}{*}{$T(K)$} & \multicolumn{3}{|c|}{ CMC $\times 10^{5}$} & \multicolumn{3}{|c|}{$\mathrm{X}_{\mathrm{CMC}} \times 10^{2}$} \\
\hline & $m^{a}=0.001$ & 0.005 & 0.010 & 0.001 & 0.005 & 0.010 \\
\hline \multicolumn{7}{|c|}{ SDS } \\
\hline 298 & 6.20 & 5.20 & 3.50 & 1.12 & 0.94 & 0.63 \\
\hline 308 & 6.75 & 5.70 & 4.50 & 1.21 & 1.03 & 0.81 \\
\hline 318 & 7.00 & 6.00 & 4.85 & 1.26 & 1.08 & 0.87 \\
\hline \multicolumn{7}{|c|}{ DTAB } \\
\hline 298.15 & 15.30 & 14.95 & 14.31 & 2.75 & 2.69 & 2.57 \\
\hline 308.15 & 15.96 & 15.35 & 14.95 & 2.87 & 2.76 & 2.69 \\
\hline 318.15 & 16.74 & 15.84 & 15.08 & 3.01 & 2.85 & 2.71 \\
\hline \multicolumn{7}{|c|}{$12-2-12$} \\
\hline 298.15 & 0.79 & 0.76 & 0.72 & 0.142 & 0.137 & 0.13 \\
\hline 308.15 & 0.89 & 0.85 & 0.80 & 0.16 & 0.153 & 0.144 \\
\hline 318.15 & 0.98 & 0.92 & 0.85 & 0.176 & 0.166 & 0.153 \\
\hline
\end{tabular}

${ }^{a} \mathrm{~m}$ is the concentration of metformin hydrochloride in water.

Standard uncertainties, $u$, are $u(T)=0.1 \mathrm{~K}, u\left({ }^{a} \mathrm{~m}\right)=0.001 \mathrm{~mol} \cdot \mathrm{kg}^{-1}$, and $u(C M C)=0.1 \mathrm{mmol} \cdot \mathrm{kg}^{-1}$. 


\subsubsection{Temperature dependence of $C M C$ or $X_{C M C}$}

The temperature dependence of $\mathrm{CMC}$ or XCMC (CMC values in mole fraction units) values of SDS, DTAB, and 12-2-12 gemini surfactants reveals the inhibitory influence of temperature on micellization of these surfactants. In general,the impact of temperature on the surfactants' CMC value may be analysed by two processes; first, the dehydration (hydrophobic and hydrophilic) of ionic head groups which may increase or decrease the $C M C$ valuesand second, as temperature rises, the structured water surrounding the nonpolar portions of the drug-surfactant may be destroyed due to intensification of molecular thermal motion, preventing aggregation and thereby raising $\mathrm{CMC}$ values. The hydrophobic and hydrophilic dehydrations show opposite behaviour towards micellization. These factors can be understood as, at low temperature, surfactants' ionic head group de-solvation has been carried out by drug molecules (hydrophilic dehydration), which encourages micellization and lowers the $C M C$ values. On the other hand, at high temperature Surrounding the non-polar region of surfactants with structured water and breaking hydrogen bonds (hydrophobic dehydration) between distinct species in the system that prevent micelle formation. Both types of hydration have been shown to decrease when the temperature rises. Thus, the magnitude of these two types of dehydrations is decisive factor in the overall magnitude of CMC $\left(X_{C M C}\right)$ values over a specific temperature range.

The temperature dependency of $C M C$ or $X_{C M C}$ (CMC in molefraction units) values as a function of temperature of DTAB and 12-2-12 gemini surfactant inthe presence of $\mathrm{Mfm}-\mathrm{HCl}$ is constructed in fig. 2.

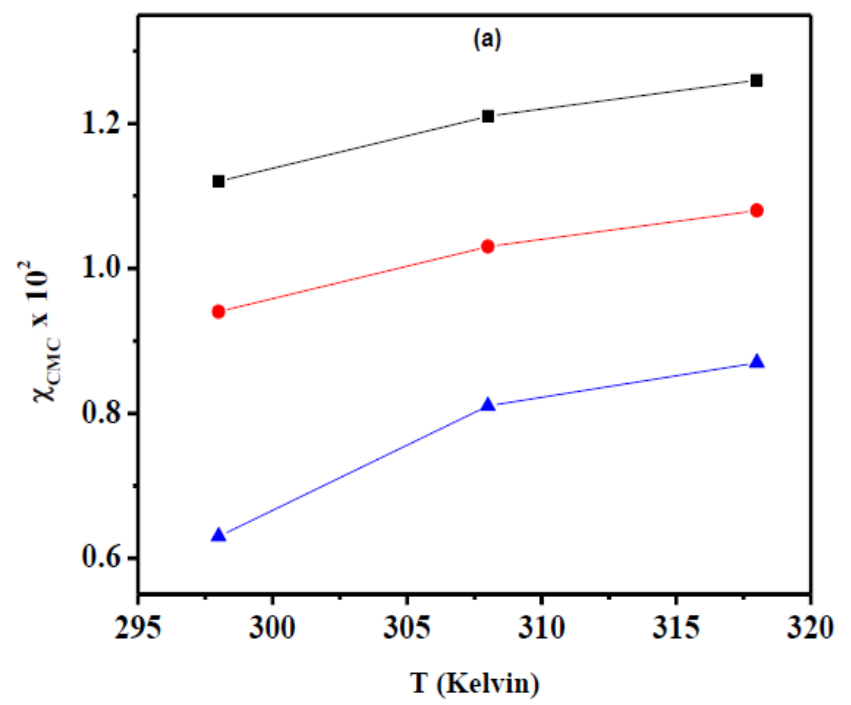

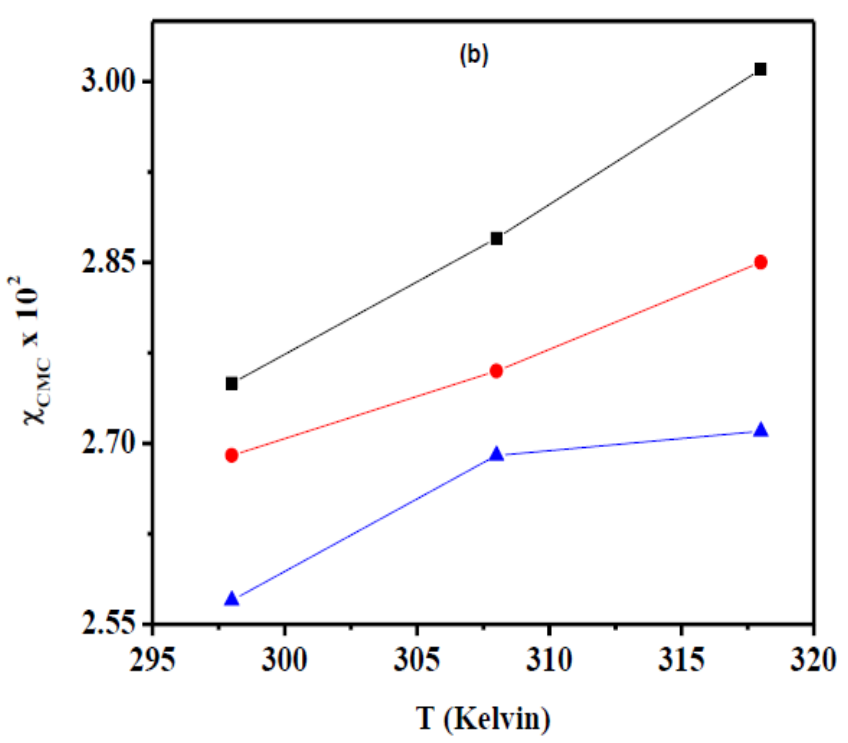

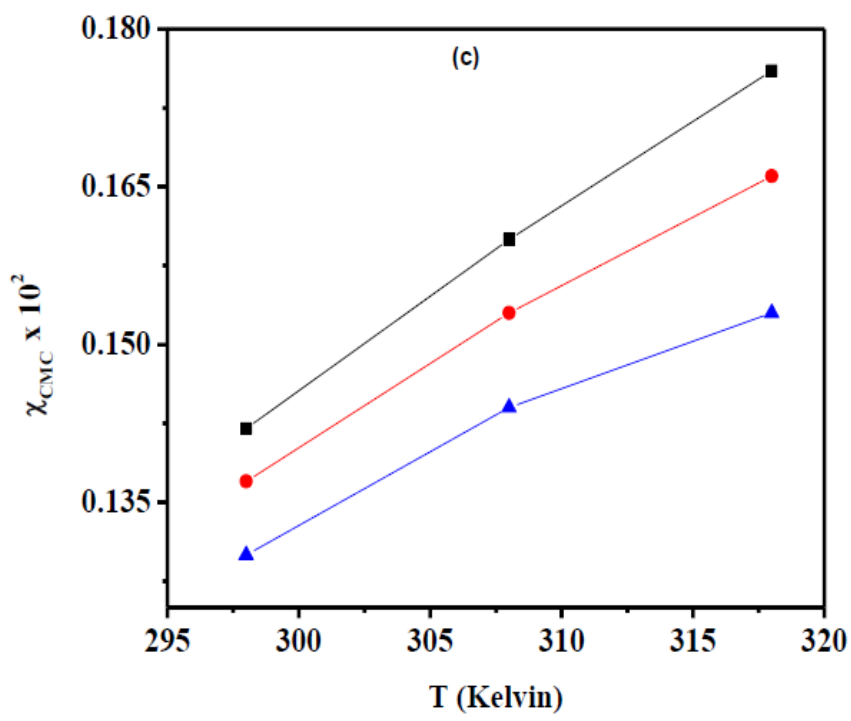

Fig. 2:Plots of $X_{C M C}$ versus temperature for a) SDS b) DTAB and c) 12-2-12 gemini surfactant; in $0.001(\square), 0.005(\bullet)$ and 0.010 ( $\Delta$ ) $\mathrm{mol} \cdot \mathrm{kg}^{-1}$ aqueous solutions of metformin hydrochloride.

Interestingly, for the present caseCMC (XCMC) values have been found to increase as temperature rises (table $1)$, indicating that the hydrophobic core is dehydrated, delaying micellization process [46]. This increase in $\mathrm{CMC}$ values at higher temperatures could be owing to the continuous increasing rupture of the water structure around the hydrophobic region of the surfactant molecules that oppose micelle formation, resulting in a rise in $\mathrm{CMC}$ values [47].

Furthermore, as temperature rises, heat as a source of energy rises, increasing the kinetics motion of surfactant molecules, and collisions reduce the likelihood of surfactant molecules to aggregate into micelles. 


\subsubsection{Thermodynamics of Micellization of SDS, DTAB and 12-2-12 Gemini surfactants}

The information on the thermodynamics of the micellization of all three categories of considered surfactants i.e. anionic (SDS) cataionic (DTAB) and dimeric (12-2-12 gemini surfactant) in the existence of metformin hydrochloride has been discussed in terms of numerous thermodynamic parameters such as standard enthalpy, $\Delta H_{m}^{o}$ free energy, $\Delta G_{m}^{o}$ and entropy, $\Delta S_{m}^{o}$ of micellization. The information on the energetic and spontaneity of micellization process of these surfactants has been gathered by analyzing $X_{C M C}$ data to calculate the said parameters.

The standard enthalpy of micellization $\Delta H_{m}^{o}$, is given by the equation[48]

$$
\Delta H_{m}^{o}=-R T^{2}\left[d \ln \left(X_{C M C}\right) / d T\right]_{P}
$$

wherethe slope of the straight line obtained by graphing $\ln (\mathrm{XCMC})$ against $\mathrm{T}$ and applying the data to a leastsquares treatment was used to compute $d\left(\ln X_{\text {CMO }}\right) / d T$. The standard free energy of micellization, $\Delta G_{m}^{o}$ and entropy of micellization, $\left(\Delta S_{m}^{o}\right)$ have been calculated from the following equations [49]

$$
\begin{gathered}
\Delta G_{m}^{o}=R T \ln \left(X_{C M C}\right) \\
\Delta G_{m}^{o}=\Delta H_{m}^{o}-T \Delta S_{m}^{o}
\end{gathered}
$$

Table 2 summarises the results of $\Delta H_{m}^{o}, \Delta G_{m}^{o}$ and $\Delta S_{m}^{o}$ of SDS, DTAB, and 12-2-12 in 0.001, 0.005, and 0.01 $\mathrm{m}$ aqueous solutions of metformin hydrochloride ( $\mathrm{Mfm}$ $\mathrm{HCl})$ at various temperature. A close perusal of table 2; infers that $\Delta G_{m}^{o}$ value for SDS, DTAB and 12-2-12 Gemini surfactants are negative $\left(\Delta G_{m}^{o}<0\right)$ over the entire studied temperature range. This finding suggests that micellization of these surfactants in the presence of $\mathrm{Mfm}-\mathrm{HCl}$ is a spontaneous occurrence. The negative magnitude of $\Delta G_{m}^{o}$ enhances with increase in content of drug as well as with rise in temperature signifying more feasible micillaztion with temperature and drug concentration. Also, the nature of surfactant affects the negative $\Delta G_{m}^{o}$ values and follow the order DTAB $<$ SDS $<12-2-12$ gemini surfactant (maximum negative) advocating the most spontaneity in micellization of 12-212 gemini surfactant indicating the presence of stronger micellization driving forces in case of later one.

Table 2:Standard thermodynamic parameters $\Delta H_{m}^{o}, \Delta G_{m}^{o}$ and $\Delta S_{m}^{o}$ of micellization for SDS, DTAB and

\begin{tabular}{|c|c|c|c|c|c|c|c|c|c|}
\hline $\mathrm{T} / \mathrm{K}$ & \multicolumn{3}{|c|}{$\Delta \mathrm{G}_{\mathrm{m}}^{\circ}\left(\mathrm{kJ} \mathrm{mol}^{-1}\right)$} & \multicolumn{3}{|c|}{$\Delta \mathbf{H}_{\mathrm{m}}^{\circ}\left(\mathrm{kJ} \mathrm{mol}^{-1}\right)$} & \multicolumn{3}{|c|}{$\Delta \mathbf{S}_{\mathrm{m}}^{\circ}\left(\mathrm{J} \mathrm{K}^{-1} \mathrm{~mol}^{-1}\right)$} \\
\hline \multicolumn{2}{|c|}{$\mathrm{m}^{\mathrm{a}}=0.001$} & 0.005 & 0.01 & 0.001 & 0.005 & 0.01 & 0.001 & 0.005 & 0.01 \\
\hline \multicolumn{10}{|c|}{ SDS } \\
\hline 298.15 & -22.25 & -22.63 & -23.16 & -2.405 & -2.403 & -2.402 & 66.58 & 67.87 & 69.64 \\
\hline 308.15 & -23.09 & -23.52 & -24.13 & -2.487 & -2.486 & -2.484 & 66.88 & 68.29 & 70.26 \\
\hline 318.15 & -24.06 & -24.53 & -25.57 & -2.570 & -2.568 & -2.565 & 67.58 & 69.05 & 72.35 \\
\hline \multicolumn{10}{|c|}{ DTAB } \\
\hline 298.15 & -20.31 & -20.37 & -20.48 & -2.411 & -2.411 & -2.410 & 60.06 & 60.26 & 60.62 \\
\hline 308.15 & -20.88 & -20.98 & -21.05 & -2.494 & -2.494 & -2.494 & 59.7 & 60.03 & 60.25 \\
\hline 318.15 & -21.44 & -21.58 & -21.71 & -2.578 & -2.577 & -2.577 & 59.3 & 59.76 & 60.17 \\
\hline \multicolumn{10}{|c|}{ 12-2-12 } \\
\hline 298.15 & -27.65 & -27.75 & -27.88 & -2.388 & -2.387 & -2.387 & 84.78 & 85.10 & 85.55 \\
\hline 308.15 & -28.27 & -28.39 & -28.55 & -2.472 & -2.471 & -2.471 & 83.78 & 84.16 & 84.66 \\
\hline 318.15 & -28.94 & -29.11 & -29.31 & -2.555 & -2.555 & -2.554 & 82.96 & 83.49 & 84.15 \\
\hline
\end{tabular}
12-2-12 gemini surfactant in $\left(\mathrm{m}^{\mathrm{a}}=\mathbf{0 . 0 0 1}, 0.005\right.$ and 0.010$) \mathrm{mol} \cdot \mathrm{kg}^{-1}$ aqueous solutions of metformin hydrochloride at different temperatures $(\mathrm{T} / \mathrm{K})$

${ }^{a} m$ is the concentration of Mfm-HClin water. Standard uncertainties, $u$, are $u(T)=0.1 \mathrm{~K}, u\left(\Delta G_{m}^{o}\right)=0.3 \mathrm{~kJ} \cdot \mathrm{mol}^{-1}, u\left(\Delta H_{m}^{o}\right)=0.4 \mathrm{~kJ} \cdot \mathrm{mol}^{-1}$, and $u\left(\Delta S_{m}^{o}\right)=0.01 \mathrm{~kJ} \cdot \mathrm{K}^{-1} \cdot \mathrm{mol}^{-1}$.

The $\Delta H_{m}^{o}$ values are also found to be negative under all the studied experimental conditions. The negative values of standard enthalpy of micellization suggest that the process is exothermic in nature which may be considered to be indicative of that the presence of
London dispersion forces in drug-surfactants system and play important role in micellization process. From table 2, it is clear that $\Delta H_{m}^{o}$ values are becoming more negative, which could be attributed to the reason with rise in temperature the breaking of hydrogen bonding in 
the solvent occurs and hence reduces the energy requirement to break water cluster and it becomes more easier for surfactant molecules to come closer to each other i.e. easy micellization [50]. Subsequently, the $\Delta H_{m}^{o}$ valuesincrease with content of drug however to small extentsuggesting lesser enthalpic contribution towards micellization. The negative magnitude follows the order:DTAB $>12-2-12$ geminisurfactant $>$ CTAB signifying thatin the case of DTAB, enthalpy has the most impact on the micellization process.

The $\Delta S_{m}^{o}$ values have been found to be positive for all the studied surfactants confirms thataggregation is entropically favored which on first thought may be against the theoretical aspects as micellization is the process of forming a more ordered structure from monomeric surfactant molecules. As a result, the expected entropy change is negative. Its positive value, on the other hand, shows the melting of iceberg clusters surrounding the surfactant monomer's hydrocarbon tails and an increase in the unpredictability of the hydrocarbon chains in the micellar core. Comparatively $\Delta S_{m}^{o}$ values follow the order:DTAB $<\mathrm{CTAB}<12-2-$ 12 gemini surfactant suggesting that the entropic contribution towards micellization is strongest for 12-212 gemini surfactant. Also the total of the enthalpic $\left(\Delta H_{m}^{o}\right)$ and entropic $\left(-T \Delta S_{m}^{o}\right)$ contributions provides the value of $\Delta G_{m}^{o}$. The results in tables 2, show that negative values of $\Delta G_{m}^{o}$ are mostly owning to the large positive value of $\Delta S_{m}^{o}$ implying a stronger pushing force for micellization.

\subsection{Fluorescence Probe Studies}

In the study of micellar aggregates and membranes, fluorescence probe analysis is becoming increasingly essential [51, 52]. Pyrene has been frequently used among other fluorescent probes due to several intriguing photo-physical properties such as probe, particularly the long life-time of pyrene monomers and effective generation of excimers. Furthermore, pyrene is a very hydrophobic probe with a poor water solubility. Pyrene is preferentially solubilized in the interior hydrophobic areas of micelles and other macromolecular systems when these aggregates are present. As a result, we developed the pyrene fluorescence spectra for determining the CMC of SDS, DTAB, and 12-2-12 gemini surfactant in $\mathrm{Mfm}-\mathrm{HCl}$ aqueous medium. The ratio of the intensities of the first to third major vibrational peaks $\left(I_{1} / I_{3}\right)$ in the fluorescence spectrum of pyrene is frequently employed as a measure of the polarity in the probe's surroundings. [53]. This (I1/I3) ratio, often known as the "Py scale" [54], is a measure of changes in the pyrene microenvironment. Because of its low solubility in water compared to a hydrophobic environment, it is rapidly distributed into micelle interiors as soon as they form, and the transfer is accompanied by a sharp decrease in the $\mathrm{I} 1 / \mathrm{I} 3$ ratio, one would expect that when a surfactant is added to an aqueous solution containing pyrene, the onset of micelle formation would be visible. Because of its low solubility in water compared to a hydrophobic environment, it is rapidly distributed into micelle interiors as soon as they form, and the transfer is accompanied by a sharp decrease in the $I_{1} / I_{3}$ ratio, one would expect that when a surfactant is added to an aqueous solution containing pyrene, the onset of micelle formation would be visible. The profile of $I_{1} / I_{3}$ versus [surfactant] has been found to be sigmoidal in nature as can be observed from fig. 3 and analyzed according to Sigmoidal-Boltzmann equation (SBE) to determine CMC values of the considered surfactants. The obtained values have been indexed in table 3 along with $C M C$ values determined from conductivity studies for comparison purpose.

Table 3:Experimentally determined $C M C$, values of SDS, DTAB and 12-2-12 Gemini surfactant SDBS and DTAB in aqueous solutions of $\mathrm{Mfm}-$ $\mathrm{HCl}$ at room temperature

\begin{tabular}{cccc}
\hline & \multicolumn{3}{c}{$\mathbf{C M C}^{\mathbf{2}} \mathbf{1 0}^{\mathbf{3}}$} \\
\cline { 2 - 4 } $\mathbf{m}^{\mathbf{a}}$ & SDS & DTAB & $\begin{array}{c}\mathbf{1 2 - 2 - 1 2} \\
\text { Gemini } \\
\text { surfactant }\end{array}$ \\
\hline $\mathbf{0 . 0 0 1}$ & $6.21(6.20)$ & $15.31(15.30)$ & $0.78(0.79)$ \\
\hline $\mathbf{0 . 0 0 5}$ & $5.21(5.20)$ & $14.93(14.95)$ & $0.77(0.76)$ \\
\hline $\mathbf{0 . 0 1 0}$ & $3.52(3.50)$ & $14.29(14.31)$ & $0.72(0) .72$ \\
\hline
\end{tabular}

Values in the parenthesis are from conductance measurements

The usefulness of the pyrene fluorescence approach was reported by Kalyansundaran and Thomas [55] based on plots between the $I_{1} / I_{3}$ and [surfactant]. The plots of the pyrene $\mathrm{I} 1 / \mathrm{I} 3$ ratio as a function of surfactant concentration show a typical sigmoidal decline around $\mathrm{CMC}$, as is widely known. In present study (Fig. 3), the features are also sigmoidal in nature. Similar profiles have also been reported in literature [45, 56]. The pyrene $I_{1} / I_{3}$ ratio value below $\mathrm{CMC}$ indicates a polar climate. The pyrene $\mathrm{I} 1 / \mathrm{I} 3$ ratio reduces fast as the surfactant concentration rises, indicating that the pyrene 
is perceiving a more hydrophobic environment. Because the probe is incorporated into the micelles' hydrophobic region above $\mathrm{CMC}$, the pyrene $\mathrm{I} 1 / \mathrm{I} 3$ ratio reaches a relatively constant value.

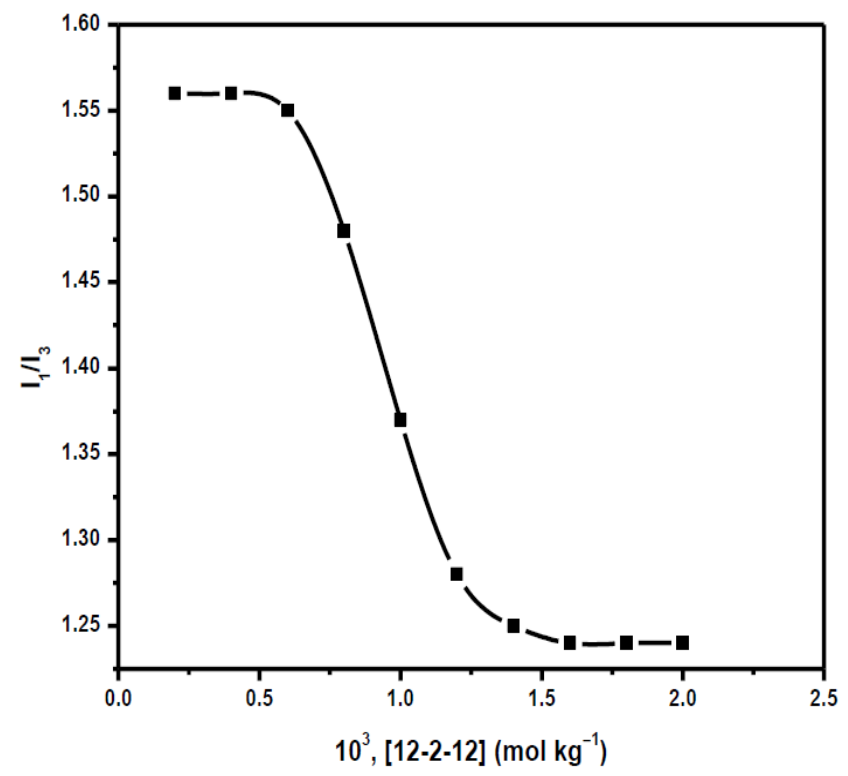

Fig. 3:Representative sigmoidal plots of $I_{1} / I_{3}$ for 12-2-12 gemini surfactant in case of $0.005 \mathrm{M}$ $\mathrm{Mfm}-\mathrm{HCl}$ at room temperature

\section{CONCLUSIONS}

The micellar behaviour two conventional surfactants viz. sodium dodecylsulphate (anionic) and dodecyltrimethylammonium bromide (cationic) and one synthesized 12-2-12 gemini surfactant has been characterized in the existence of metformin hydrochloride (antidiabetic drug) with the help of conductivity measurements. The conductivity data is examined in terms of $C M C$ values of these surfactants. It was discovered that metformin hydrochloride reduces $C M C$ of the surfactants and showed the mentioned order:0.001 $>0.005>0.010 \mathrm{~mol} \cdot \mathrm{kg}^{-1}$ aqueous solution of drug, which has been suggested due to hydrophobic interactions. Moreover, the effect of temperature on micellization of studied surfactants has been studied by carrying conductivity measurement at 298.15, 308.15 and $318.15 \mathrm{~K}$. It has been detected that $C M C$ of all the surfactants increases with rise in temperature and has been explained in terms of hydropillic/hydrophobic dehydrations. In addition, energetic of micellization in terms of various thermodynamic parameters has been analyzed that suggests spontaneity in micellization of all the considered surfactants.

\section{Declaration of competing interest}

The authors declare that they have no known competing financial interests or personal ties that may have influenced the work presented in this study.

\section{REFERENCES}

1. Rakowska J, Szczygieł, R, Kwiatkowski M, Porycka B, Radwan K, Prochaska K. F Technol., 2017; 53(3):1379-1398.

2. Barak S, Baker H. Clinical Management of Male Infertility. MDText.com, Inc.:South Dartmouth (MA), 2016.

3. Bustelo M, Pinazo A, Manresa MA, Mitjans M, Vinardell MP. Coll Surf A Physicochem Eng Asp, 2017; 532:501-509.

4. Ataci N, Sarac A. Am J Analyt Chem, 2014; 05 (01):22-27.

5. Thongngam M, McClements D J, Langmuir, 2005; 21 (1):79-86.

6. Wang X, Li Y, Wang J, Wang Y, Ye J, Yan H, Zhang J, Thomas R K. J Phys Chem B, 2005; 109 (26), 12850-12855.

7. Tadros T F, Appied Surfactants:Principles and Applications. Wiley-VCH; 2005.

8. Bendedouch D, Chen S H, Koehler W C. J Phys Chem, 1983; 87(14):2621-2628.

9. Chevalier Y, Chachaty C. Colloid Polym Sci, 1984; 262(6): 489-496.

10. Cui X, Mao S, Liu M, Yuan H, Du Y. Langmuir, 2008; 24(19):10771-10775.

11. Chakraborty T, Chakraborty I, Ghosh S. Arab J of Chem, 2011; 4(3):265-270.

12. Damen M, Cristóbal-Lecina E, Sanmartí GC, van Dongen SFM, García Rodríguez CL, Dolbnya IP, et al. Soft Matter, 2014; 10 (31):5702-5714.

13. Kwaśniewska D, Staszak K, Wieczorek D, Zieliński R. J Surf Deterg, 2015; 18(3):477-486.

14. Menger FM, Mbadugha BN. J Am Chem Soc, 2001; 123(5):875-885.

15. Menger FM, Keiper JS, Azov V. Langmuir, 2000; 16(5):2062-2067.

16. Gull N, Mir MA, Khan JM, Khan RH, Rather GM, Dar AA. J Colloid Interface Sci, 2011; 364(1):157162.

17. Bombelli C, Giansanti L, Luciani P, Mancini G. Curr Med Chem, 2009; 16(2):171-183.

18. Guo YJ, Liu J X, Zhang XM, Feng RS, Li HB, Zhang J, et al. Energy Fuels, 2012; 26(4):21162123. 
19. Block LC, Schemling LO, Couto AG, Mourão SC, Bresolin TMB. Rev ciênc farm básica apl, 2008; 29 35.

20. Gallo A, Ceolotto G, Pinton P, Iori E, Murphy E, Rutter GA, et al. Diabetes, 2005; 54(4):1123-1131.

21. Liu H, Scholz C, Zang C, Schefe JH, Habbel P, Regierer AC, et al. Anticancer Res, 2012; 32(5):1627-1637.

22. Md Zakir Sultan SF. Pharm Anal Acta, 2015; 06(03): $1-5$.

23. Harahap Y, Purnasari S Hayun, Dianpratami K, Senjaya RN. J Bioequiv Availab, 2011; 3(1):016019.

24. Triplitt C. Diabetes Spectr, 2006; 19 (4):202-211.

25. Chauhan S, Sahota A, Singh K, Singh K, Kaur M. J Mol Liq, 2017; 242:1066-1074.

26. Chauhan S, Kumar K, Singh K, Jyoti J. J Surfactants Deterg, 2014; 17(1):169-175.

27. Chauhan M S, Rajni, Chauhan S, Rana DS, Umar A. $A_{d V}$ Sci Lett, 2012; 7(1):43-51.

28. Gill DS, Kumari N, Chauhan MS. J Chem Soc Lond Faraday Trans, 1985; 81(3):687-693.

29. Syal VK, Lal G, Bisht P, Chauhan S. J Mol Liq, 1995; 63(3):317-328.

30. Syal VK, Chauhan S, Chauhan MS. IJ Chem, 1990; 29(A):693-696.

31. Yao NP, Bennion DN. J Phys Chem, 1971; 75(23):3586-3591.

32. Chauhan S, Sharma V, Singh K, Chauhan MS, Singh K. J Mol Liq, 2016; 222:67-76.

33. Pal A, Chaudhary S. Colloids Surf A Physicochem Eng Asp, 2013; 430:58-64.

34. Beiginejad H, Bagheri A, Yekta LS, Nojini ZB. J Incl Phenom Macrocycl Chem, 2010; 67(3):247-252.

35. Singh HN, Swarup S, Saleem SM. J Colloid Interface Sci, 1979; 68(1):128-134.

36. Akhtar F, Hoque MA, Khan MA.J Chem Thermodyn, 2008; 40(7):1082-1086.

37. Das S, Mondal S, Ghosh S. RSC Adv. 2016; 6(37):30795-30803.
38. Oremusová J, Vitková Z, Vitko A, Tárník M, MikloviČová E, Ivánková O, et al. Molecules, 2019, 24(3):5-12.

39. Matsuki H, Aratono M, Kaneshina S, Motomura K. J Colloid Interface Sci, 1997; 191(1):120-130.

40. Sarmiento F, López-Fontán JL, Prieto G, Mosquera V, Attwood D. Colloid Polym Sci, 1997; 275(12):1144-1147.

41. Haque ME, Das AR, Moulik SP. J Colloid Interface Sci, 1999; 217 (1):1-7.

42. Bakshi MS. BCSJ, 1996; 69(10):2723-2729.

43. Treiner C, Makayssi A. Langmuir, 1992; 8(3): 794 800.

44. Ali A, Nabi F, Malik NA, Tasneem S, Uzair S. J Surfactants Deterg, 2013; 17(1):565-573.

45. Chauhan S, Singh K, Sundaresan CN. J Mol Liq, 2018; 266:692-702.

46. Palepu R, Gharibi H, Bloor DM, Wyn-Jones E. Langmuir, 1993; 9(1):110-112.

47. Ruiz CC, Molina-Bolívar JA, Aguiar J, MacIsaac G, Moroze S, Palepu R. Langmuir, 2001; 17(22):68316840.

48. Singh HN, Saleem SM, Singh RP, Birdi KS. J Phys Chem, 1980; 84(17):2191-2194.

49. del Rio JM, Pombo C, Prieto G, Mosquera V, Sarmiento F. J Colloid Interface Sci, 1995; 172(1):137-141.

50. Chavda S, Kuperkar K, Bahadur P. J Chem Eng Data, 2011; 56(5):2647-2654.

51. Basu Ray G, Chakraborty I, Moulik SP. J Colloid Interface Sci, 2006; 294(1):248-254.

52. Azum N, Rub MA, Asiri A M, Kashmery HA. J Mol Liq, 2018; 260:159-165.

53. Lu T, Lan Y, Liu C, Huang J, Wang Y. J Colloid Interface Sci, 2012; 377(1):222-230.

54. Morrisett JD, Pownall HJ, Plumlee RT, Smith LC, Zehner ZE, Biol Chem, 1975; 250 (17):6969-6976.

55. Kalyanasundaram K, Thomas JK, J Am Chem Soc, 1977; 99(7):2039-2044.

56. Singh K, Chauhan S. J Mol Liq, 2020; 316:113833. 